\title{
Comparative Study between Bone Flap Insertion in Abdominal Wall Versus Flail Replacement in Decompressive Craniectomy of Acute Subdural Hematoma
}

\author{
AHMED S.K. ABD EL-WAHED, M.D. \\ The Department of Neurosurgery, Faculty of Medicine, Cairo University, Egypt
}

\begin{abstract}
Background: Traumatic acute subdural hematoma remains one of the most lethal of all head injuries patients with Acute Subdural Hematomas (ASDHs) having higher mortality and lower functional recovery rates compared with those of other head-injured patients.
\end{abstract}

Decompressive Craniectomy (DC) for management of ASDH with accompanying brain edema and midline shift has become one of the standard guidelines in many centers. DC remains to be the standard of surgical modality for patients with poor clinical status.

Subcutaneous preservation of autologous bone flap is an inexpensive option that preserves the viability of the bone flap, resulting in good cosmetic results and the very low infection rate.

Aim of Study: To compare results of (ASDHs) managed with DC with consequent subcutaneous bone flap insertion in the abdominal wall vs subcutaneous hinged flail placement in the craniectomy site.

Patients and Methods: A retrospective review of 61 patients with (ASDHs) operated at the Department of Neurosurgery, Cairo University and Beni Souf University Hospital during the period from Jan. 2012 - Dec. 2015. Patients were divided into:

Group (A): 31 patients operated upon with subcutaneous abdominal bone flap insertion, (22 males and 9 females) median age was 42 years. On admission there were 19 patients with Glasgow Coma Score (GCS) below 8, and 12 patients with GCS 8 or above 8 .

Group (B): 30 patients operated upon with subcutaneous hinged flail bone flap replacement in the craniectomy site, ( 22 males and 8 females) median age 44 years. On admission there were 18 patients with GCS blew 8, and 12 patients with GCS 8 or above 8 .

Early surgical evacuation, dural fenestration, intensive care management to monitor intra cranial pressure and followup CT brain were done for all patients.

Correspondence to: Dr. Ahmed S.K. Abd El-Wahed, E-Mail: Askamel@.gmail.com
Results: Group (A) 14 patients died in the hospital, 4 survived with unfavorable outcome (vegetative state), and 13 survived with favorable outcome.

Group (B) 17 patients died in the hospital, 4 survived with unfavorable outcome (vegetative state), and 9 survived with favorable outcome.

Conclusion: Analysis of the obtained data reveals that subcutaneous abdominal bone flap insertion shows a statistically significant better prognosis as compared to subcutaneous hinged flail bone flap replacement at the craniectomy site which may be due to better decompression of the brain and allowing for more roomfor expansion.

Key Words: Bone flap - Abdomen - ASDH - Decompressive craniectomy.

\section{Introduction}

TRAUMATIC acute subdural hematoma remains one of the most lethal of all head injuries patients with Acute Subdural Hematomas (ASDHs) have higher mortality and lower functional recovery rates compared with those of other head-injured patients [1-3]

Decompressive Craniectomy (DC) is performed in patients suffering from intractable elevation of ICP following infarction or bleeding (e.g ASDH) [6]. Despite increasing evidence regarding the benefits of the procedure [4-7], there are no standard guidelines for how to perform DC. Many options exist, from complete removal of the bone to be stored in a bone banking facility to descriptions of in situ hinge craniectomies in which the bone flap is not removed but hinged to the cranium,other authors inserted the bone subcutaneously in the abdominal wall to be stored till intracranial tension normalizes [8-11]

It remains controversial however, whether it is better to leave the bone hinged to the cranium or 
insert it subcutaneously in the abdominal wall [12-1 6].

\section{Aim of the study:}

The aim of this study is to compare results of (ASDHs) managed with DC plus Dural Fenestration (DF) with consequent subcutaneous bone flap insertion in the abdominal wall vs subcutaneous flail hinged placement in the craniectomy site.

\section{Patients and Methods}

A retrospective review of 61 patients with (ASDHs) operated upon at the Department of Neurosurgery, in Cairo University Hospitals and Beni Sueif University Hospital during the period from Jan. 2012 - Dec. 2015.

\section{Patients were divided into two groups:}

Group (A): 31 patients operated upon with subcutaneous abdominalbone flap insertion, (22 males and 9 females) median age was 42 years. On admission there were 19 patients with Glasgow Coma Score (GCS) below 8, and 12 patients with GCS 8 or above 8 .

$\operatorname{Group}(B): 30$ patients operated upon with subcutaneous flail bone flap replacement in the craniectomy site, (22 males and 8 females) median age 44 years. On admission there were 18 patients with GCS blew 8 , and 12 patients with GCS 8 or above 8 .

Early surgical evacuation, dural fenestration, intensive care management to monitor and manage intra cranial pressure and next morning follow-up CT brain were done for all patients.

\section{Pre-operative clinical status:}

To evaluate the results of management it is imperative to accurately examine the clinical condition prior to surgery. All patients were examined for conscious level, signs of brain-stem dysfunction, and alteration of vital signs, pupils, motor power were also noted along with detailed history about the patient's medical conditions, mode of trauma and time lapsed before admission. All patients were subjected to early urgent CT brain, ICU admission, rapid cerebral dehydration, \& preparation for urgent surgery.

\section{Operative procedure:}

When the clinical diagnosis of a large unilateral subdural hematoma as the primary intracranial mass lesion was confirmed, the following surgical procedure was employed: Under general endotracheal anesthesia, a high temporal burr hole was placed to provide an immediate release of intrac- ranial pressure and, in addition, to exclude the possibility of a subacute hematoma that could be evacuated through a conventional opening. When an acute subdural was encountered, a skin flap was extended from the glabella along the midline, terminating $4 \mathrm{~cm}$ above the external occipital protuberance. The skin incision was carried laterally to the level of the transverse sinus, and a one-layer myo-cutaneous flap including the periosteum was turned. A frontoparietal, occipital, and temporal bone flap was then removed to reveal almost the entire surface of the hemisphere; this was rapidly accomplished by the use of the high-speed pneumatic craniotome when available and Hudson brace together with giggly saws in other cases. The squamous temporal bone was rongeured to the floor of the temporal fossa, making absolutely certain that no edge of bone remained that might prevent subsequent lateral displacement of swollen temporal lobe. The bone flap was either left hinged subcutaneously at the craniotomy site or placed subcutaneously on the abdominal wall. Dura was not opened and the hematoma was evacuated by many fenestrations.

Through this exposure it was possible to carry out a complete removal of all clotted and liquid hematoma. Bleeding points were controlled by surgicel and gel foam, when hemostasis was satisfactory, there was no attempt to close the dura. An epidural or subgalial drain was placed and connected to a closed, sterile, non pressurized drainage system (which was removed after 24 to 36 hours). The scalp was closed in two layers using subugaleal vicryl 3.0 and skin proline 2.0 mattress sutures.

\section{Post-operative care:}

In the post-operative period respiratory assistance was maintained, as indicated by changes in blood gases and ventilator parameters. Antibiotics were given as a standard peri operative prophylaxis using Cephotriaxone 1 gram IV, any other antibiotics were given only when needed to combat specific infections of respiratory, urinary, or central nervous system origin. Steroids were not administered; IV anticonvulsants were given to all patients as soon as the diagnosis was made and maintained although management course.

\section{Results}

Patient characteristics, including age, sex, andpre-existing medical conditions together with site and side of ASDH; and presence of trans-tentorial herniation according to the primary admission CT and diagnosis. 


\section{Patients were divided into two groups:}

Group (A): 31 patients operated upon with subcutaneous abdominalbone flap insertion, (22 males and 9 females) median age was 42 years. On admission there were 19 patients with Glasgow Coma Score (GCS) below 8, and 12 patients with GCS 8 or above 8 .

Group (B): 30 patients operated upon with subcutaneous flail bone flap replacement in the craniectomy site, (22 males and 8 females) median age 44 years. On admission there were 18 patients with GCS blew 8 , and 12 patients with GCS 8 or above 8 .

Combined median age of both groups was 42$45 \mathrm{ys}$, there was a total of 44 males and 17 females enrolled, 37 patients had GCS blow 8 and 24 patients had a GCS above 8. Overall clinical presentation or 37 patients with trans-tentorial herniation showed ipislateral mydriasis and contralateral weakness.

The mean time for preparation for surgery did not exceed one hour. The average time for surgical decompression plus closure was 3-4 hs over all the study. There was extra time allowed in the subcutaneous abdominal insertion group to allow for prepping, incision and closure of abdominal wound.

Group (A) 14 patients died in the hospital, 4 survived with unfavorable outcome (vegetative state), and 13 survived with favorable outcome.

Group (B) 17 patients died in the hospital, 4 survived with unfavorable outcome (vegeta- tive state), and 9 survived with favorable outcome.

Table (1): Sex distribution.

\begin{tabular}{lcc} 
& Group A & Group B \\
\hline Male & 22 & 22 \\
Female & 9 & 8 \\
\hline
\end{tabular}

Table (2): Mean age.

\begin{tabular}{|c|c|c|}
\hline & Group A & Group B \\
\hline Mean age & $30 y$ & $35 y$ \\
\hline \multicolumn{3}{|c|}{ Table (3): Pre-operative GCS. } \\
\hline & Group A & Group B \\
\hline GCS blow 8 & 19 & 12 \\
\hline GCS 8 or above & 18 & 12 \\
\hline
\end{tabular}

Table (4): Length of surgery.

\begin{tabular}{ccc}
\hline & Group A & Group B \\
\hline Period of surgery & $3 \mathrm{hs}$ & $4 \mathrm{hs}$ \\
\hline
\end{tabular}

Table (5): Outcome in both groups.

\begin{tabular}{lll}
\hline & Group A & Group B \\
\hline Died in the hospital & $14(45.1 \%)$ & $17(66.7 \%)$ \\
Vegetative state & $4(12.9 \%)$ & $4(13.3 \%)$ \\
Favorable outcome & $13(42 \%)$ & $9(30 \%)$ \\
\hline
\end{tabular}

Statistical analysis was performed by the Fisher exact test is 0.5014 . Results with a $p<0.05$ were considered statistically significant.

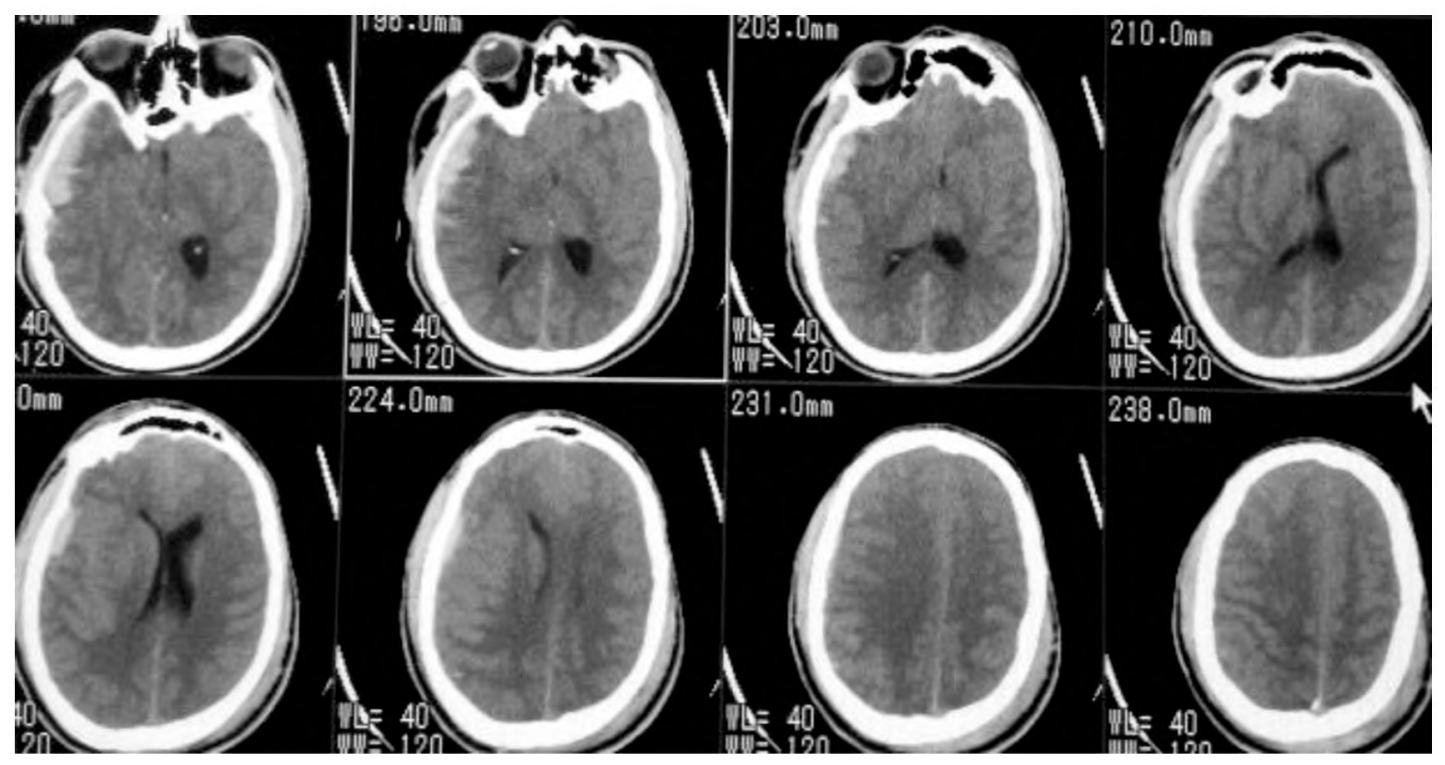

Fig. (1): Pre-oprative ct brain show Rt tempro-praital ASDH with midline shift. 


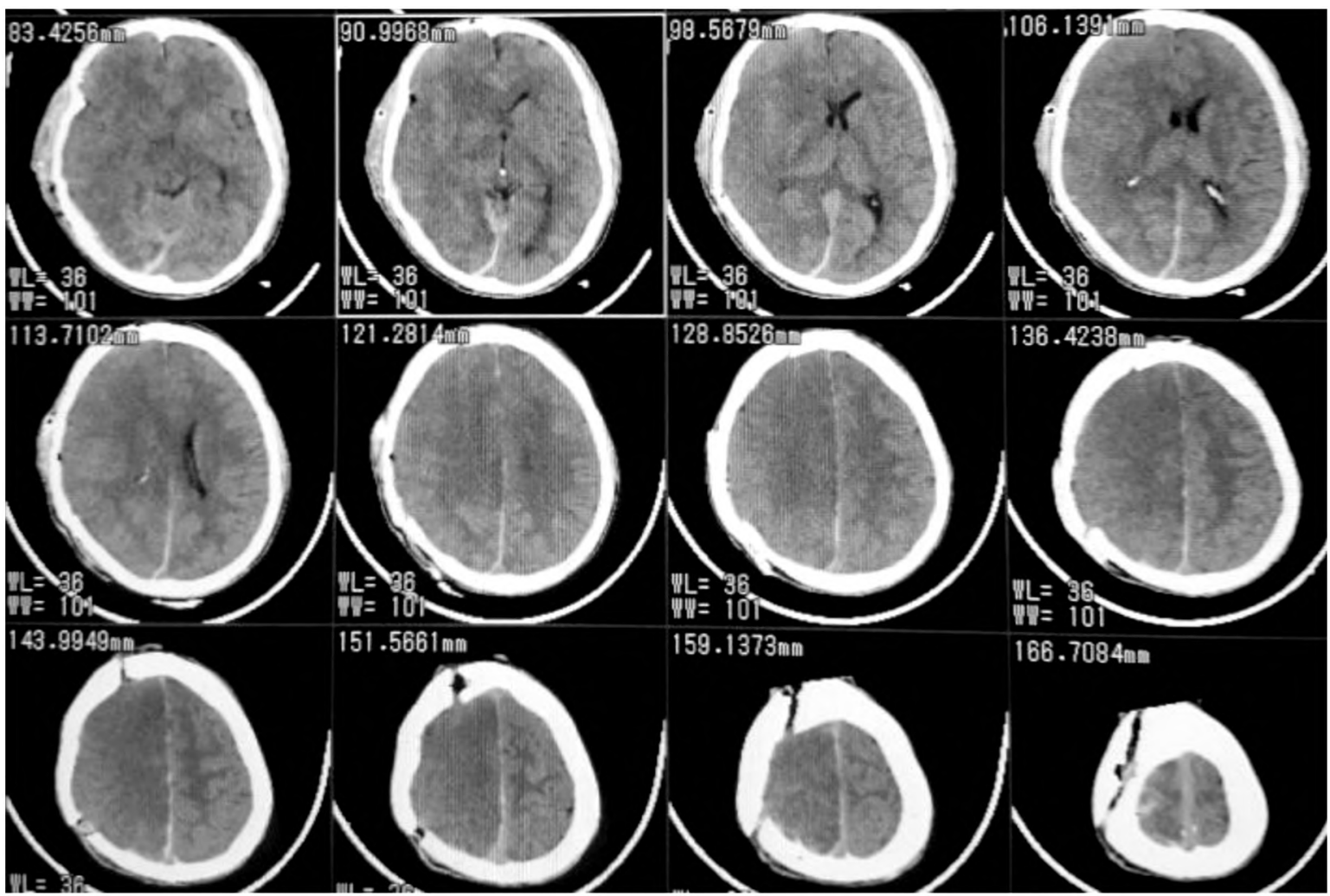

Fig. (2): Post-operative ct brain with bone hinged in temporales muscle.

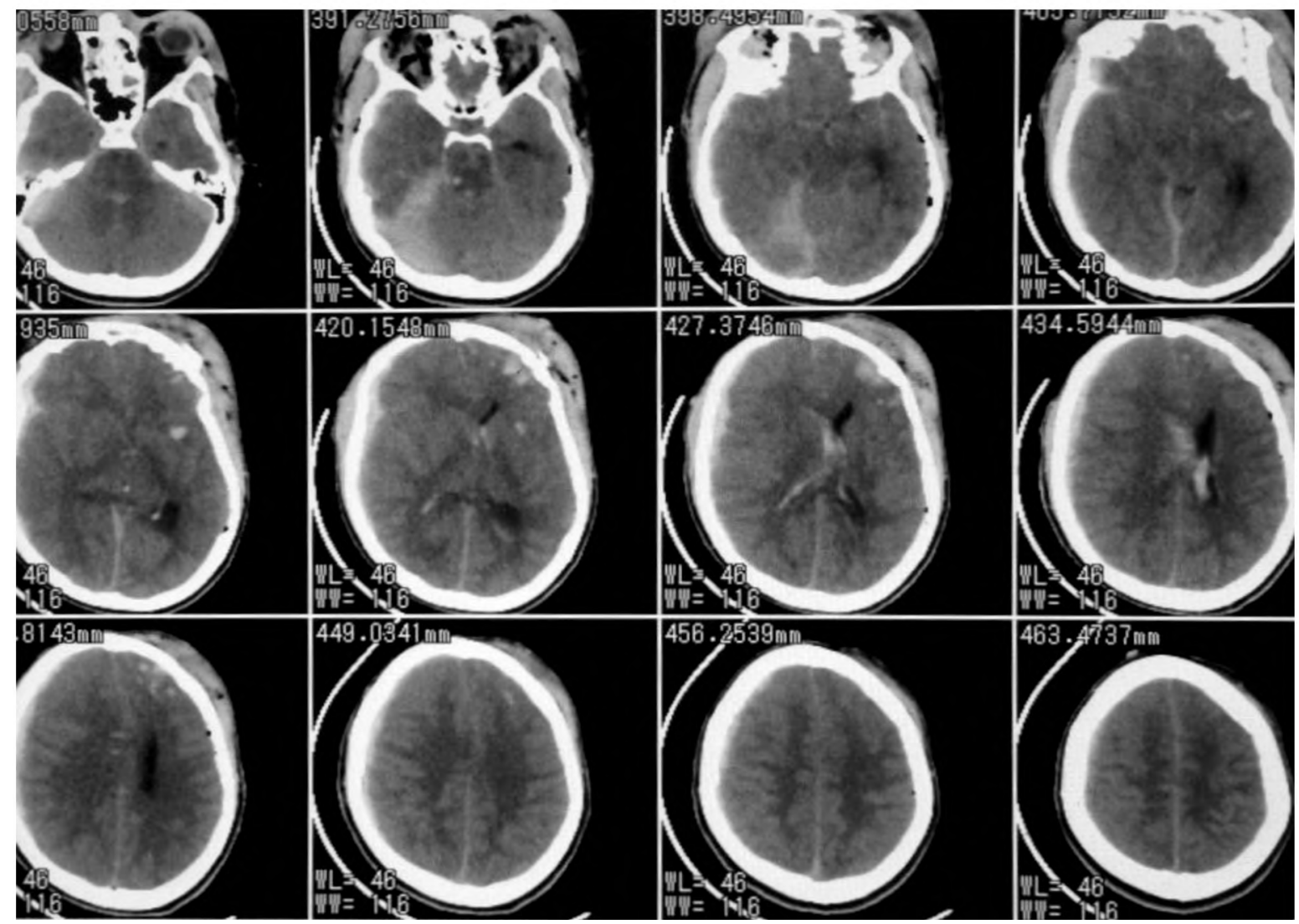

Fig. (3): Pre-oprative ct brain show Rt tempro-praital ASD with midline shift 


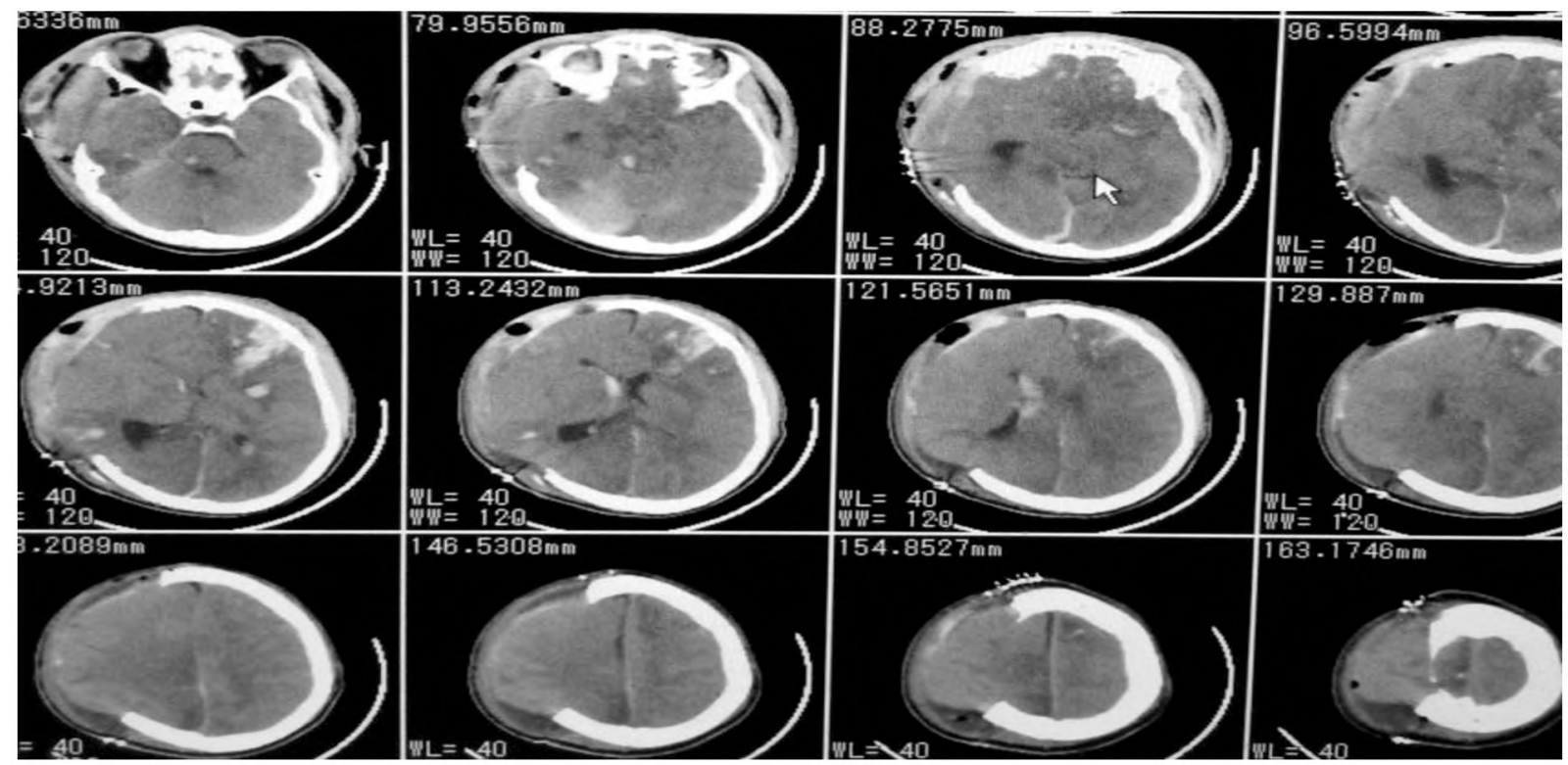

Fig. (4): Post-operative ct brain with bone inserted in abdomen.

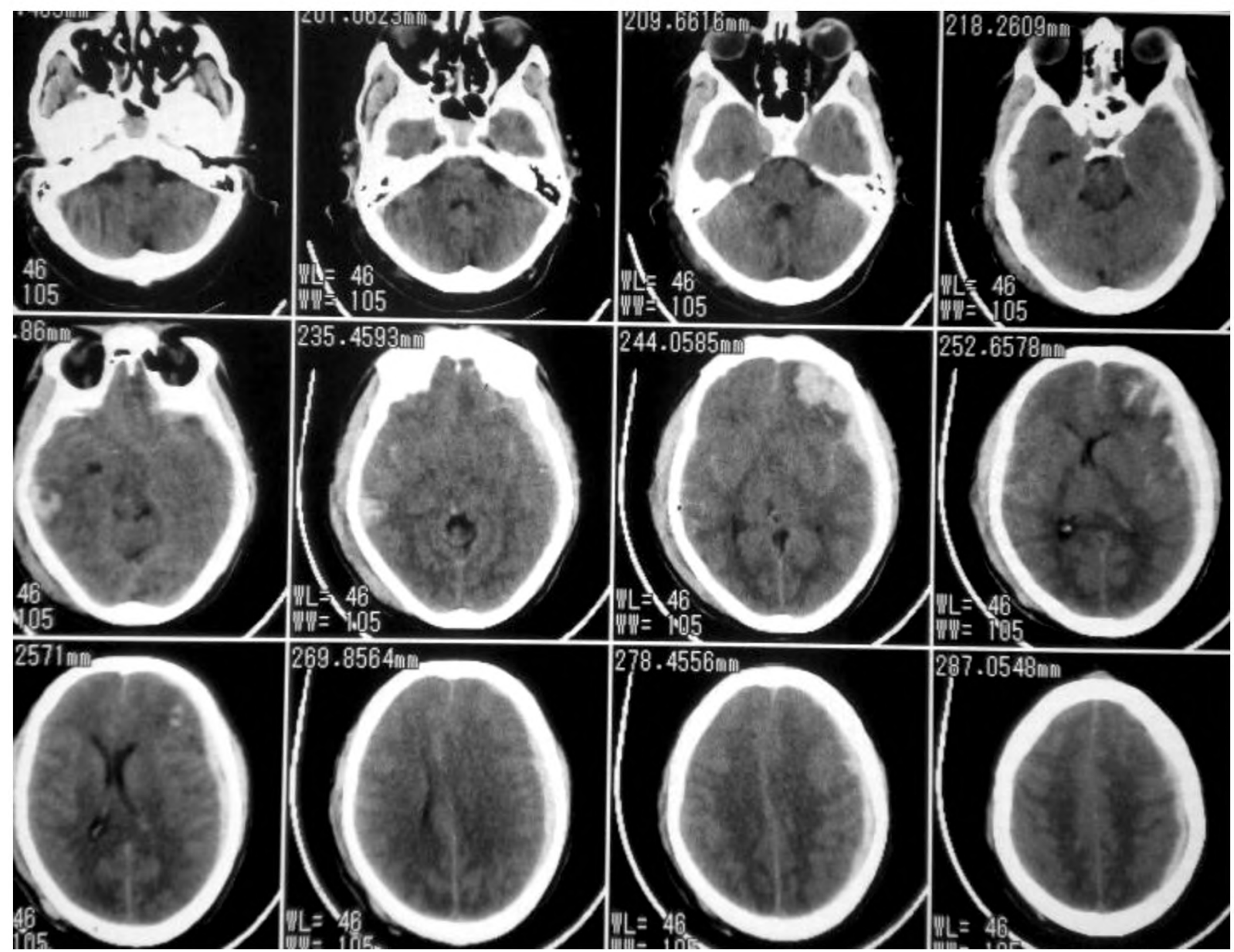

Fig. (5): Pre-oprative ct brain show lt tempro-praital ASD with midline shift. 

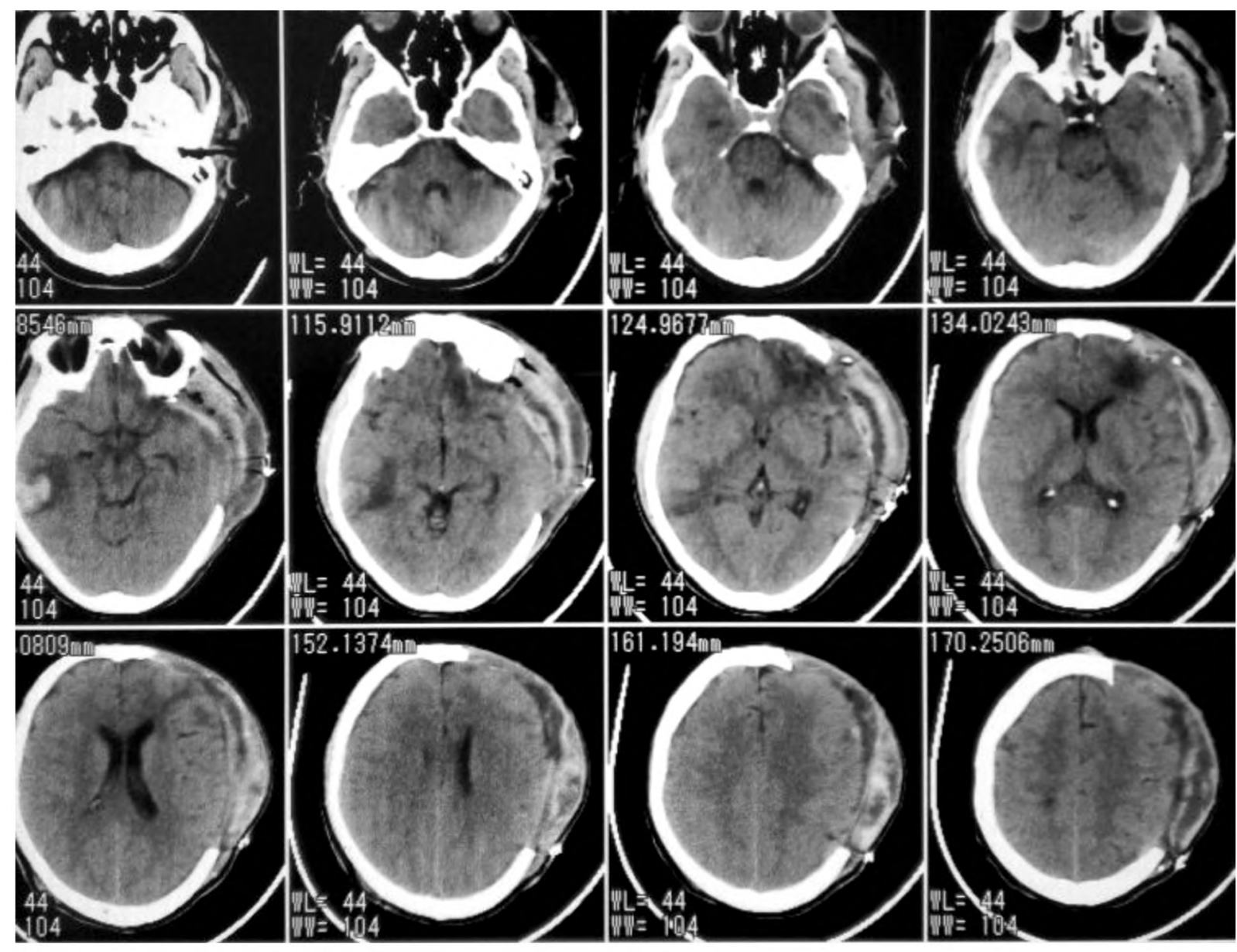

Fig. (6): Post-operative ct brain with bone inserted in abdomen.

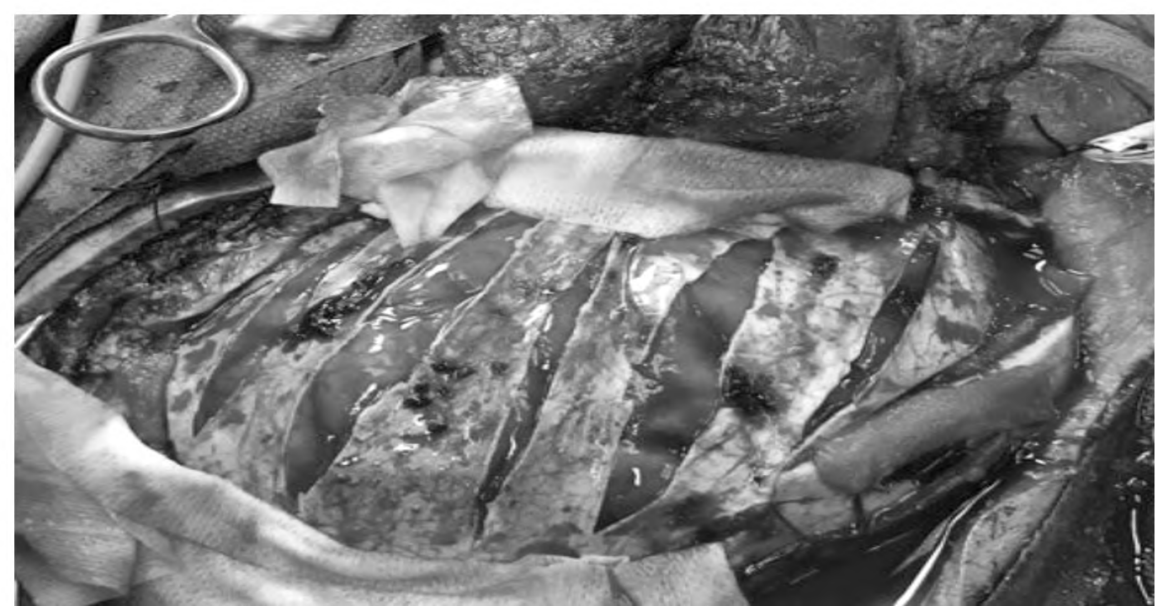

Fig. (7): Intra operative multiple dural snipes for evacation of ASDH.

\section{Discussion}

Traumatic acute subdural hematoma remains one of the most deadly of all head traumas. Patients suffering from ASDHs have higher mortality and lower functional recovery rates compared with patients with other head injuries $[\mathbf{3 , 5 , 8 , 9 ]}$.
Many surgical and non surgical techniques have been advocated in the management of ASDHs, among these burr holes, craniectomies, osteoplastic flaps, subtemporal decompression, temporal lobectomy, dural opening, dural augmentation and dural snips $[\mathbf{1 , 4 , 6 , 1 1}]$. Despite all efforts, the reported mortality rate has remained at approximately $80 \%$ 
to $90 \%$ with a very high morbidity rate among the surviving population [4-7].

Decompressive craniectomy is known to be effective in reducing refractory elevated ICP due to ASDH [2,5,12], there is controversy concerning the necessity of craniectomies in which the bone flap is not totally removed but hinged to the cranium, as compared to complete craniectomies where the bone flap is inserted in the abdominal wall.

We performed the current analysis to evaluate feasibility and to provide data for outcome after craniectomy in which the bone flap is not removed but hinged to the cranium, versus performing a craniectomy undertaking the extra step of inserting the bone in the abdominal wall.

In many cases when the tamponade effect of the clot was removed, extensive bleeding ensued from the torn veins. However, with the wide exposure, bleeding was rapidly controlled through the dural snips openedand we were not required to perform complete durotomies $[\mathbf{5 , 8 , 1 0 ]}$.

Judging the results of both groups, it is clear that taking the extra step, time and effort to place the bone flap in the abdominal wall provides a better outcome that is statistically significant.

Seelig, et al., [13] reported a mortality rate of $30 \%$ if surgery for SDH was performed within 4 hours of the accident, as compared with a $90 \%$ mortality in those who had surgery after 4 hours [18]. Our results mortality rate $45 \%-66 \%$ in both groups respectively but there is a long time until the patient arrives at the ER of our department, but time in ER did not exceed one hour in both groups, which means mortality rate become significantly lower in group (B).

Our opinion is that such a difference is due to the extra space provided by complete removal of the bone flap in a (complete) craniectomy versus the (incomplete) craniectomies where the flail hinged bone with the overlying stretched scalp still occupies some space and so provides less room for brain expansion.

The technique for hinging the bone grafts is surgically easier, has one scar, saves the patient the need for a second surgery to replace the bone graft and is cosmetically better looking. Although these advantages seem tempting this technique was proven to be inferior by our data as compared to the other option where the bone is inserted in the abdomen.
The abdominal placement technique has the advantage of a better prognosis as proven by our results but requires more surgical time, an extra abdominal scar and mandates a second surgery for bone flap replacement after the patient's condition stabilizes and the brain returns to it's normal size. $\mathrm{SDH}$.

\section{Conclusion:}

Analysis of the obtained data reveals that subcutaneous abdominal bone flap insertion shows a statistically significant better prognosis as compared to subcutaneous flail bone flap replacement at the craniectomy site which may be due to better decompression of the brain and allowing for more roomfor expansion.

\section{References}

1- ARABI B., HESDORFFER D.C., AHN E.S., ARESCO C., SCALEA T.M. and ELISENBERG: Outcome following decompressive craniectomy for malignant swelling due to severe head injury. J. Neurosurg., 104: 469-79, 2006.

2- ALBANESE J., LEONE M., ALIEZ J.R., KAYA J.M. and ANTONINI F. ALLIEZ B.: Decompressive craniectomy for severe traumatic brain injury: Evaluation of the effects at one year. Crit. Care Med., 31: 2535-8, 2003.

3- BARTH M., TUETTENBERGJ, THOME C. and WEISSARTH M.: Watertight dural closure: Is it necessary? A prospective randomized trial in patients with supratentorial craniotomies. Neurosurgery, 63: 4 Suppl: 2352-8, 2008.

4- BECK J., RABEE A., LANFERMANNH, De ROCHEMONT RDO and ZANELLA F.: Effects of balloon angioplasty on perfusion-and diffusion-weighted magnetic resonance imaging results and outcome in patients with cerebral vasospasm. J. Neurosurg., 105: 220-7, 2006.

5- BULLOK M.R., CHENSUT R., CHAJAR J., GORDON D. and HARTL R.L.: Surgical management of acute subdural hematomas. Neurosurgery, 58: 3 SupplSi-iv, S 16-S24, 2006

6- BUSHMANN U.,YONEKKAWA Y., FORTUNIATI M., CESNULIS E. and KELLE E.: Decompressive hemicraniectomy in patients with subarachnoid hemorrhage and intractable intracranial hypertension. Acta Neurochir. (Wien), 149: 59-65, 2007

7- GURESIR E., BECK J., VATTER H., SETZER M., GERLACH R. and SEIFERT V.: Subarachnoid hemorrhage and intracerebral hematoma: Incidence, prognostic factors, and outcome. Neurosurgery, 63: 1088-94, 2008.

8- GURESIR E., RAABE A. and SETZER: Decompressive hemicraniectomy in subarachnoid haemorrhage: The influence of infarction, haemorrhage and brain swelling. J. Neurol. Neurosurg. Psychiatry, 80: 799-801, 2009.

9- GURESIR E., SCHUSS P., VATTER H. and RAABE A. Decompressive craniectomy in subarachnoid hemorrhage. Neurosurg. Focus, 26: 6E4, 2009.

10- HORACZEK J.A., ZIERSKI J. and GRAEW A.: Collagen matrix in decompressive hemicraniectomy. Neurosurgery 63: 1 Suppl 1 ONS 176-ONS 181, 2008. 
11- MALLITI M., PAGE P. GURRY C., CHOMETTE E., NATAF F. and ROUX F.X.: Comparison of deep wound infection rates using a synthetic dural substitute (neuropatch) or pericranium graft for dural closure: A clinical review of 1 year. Neurosurgery, 54: 599-604, 2004.

12- SCHWAB S., STEINER T. , ASCHOFF A. and SCHWARZ L.: Early hemicraniectomy in patients with complete middle cerebral artery infarction. Stroke, 29: 1888-93, 1998.

13- SEELING J.M., BECKER D.P. and MILLER J.D.: Traumatic acute subdural hematoma. Major mortality reduction in comatose patients treated within four hours. N. Engl. J. Med., 304: 1511-8, 1981.
E. and GEORGE B.: Early decompressive surgery in malignant infarction of the middle cerebral artery: A pooled analysis of three randomised controlled trials. Lancet Neurol., 6: 215-22, 2007.

15- VAHENDI K., VICAUT E., MATEO J., ORABI M. and GUICHARD J.P.: Sequential-design, multicenter, randomized, controlled trial of early decompressive craniectomy in malignant middle cerebral artery infarction (DECIMAL Trial). Stroke, 38: 2506-17, 2007.

16- YANG X.F., WENL, SHEN F., LOU R. and LIU W.G.: Surgical complications secondary to decompressive craniectomy in patients with a head injury: A series of 108 consecutive cases. Acta Neurochir. (Wien), 150: 12418, 2008.

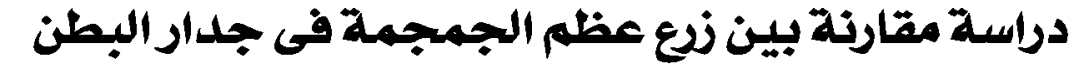

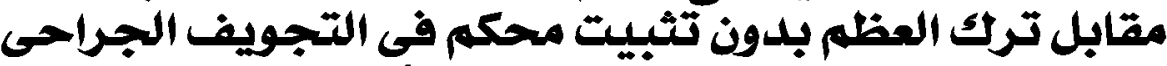

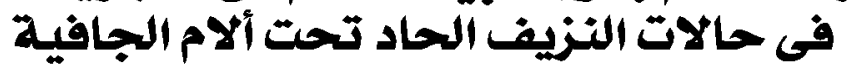

\author{
لا يزال النزيف الحاد تحت ألام الجافية يعتبر أحد أخطر الإصابات فى الرأس. وهو السبب الرئيسى فى نسب أعلى من الوفيات بالمقارنة \\ مع إصابات الرأس الأخرى. \\ الهدف من هذه الدراسة مقارنة نتيجة حالات النزيف المخى الحاد تحت ألام الجافية الذين يحتاجون لاستئصال القحف فى مجموعتين : \\ - مجموعة (أ) زدع العظام في البطن.

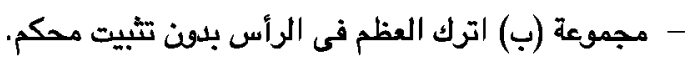 \\ تم إجراء مراجعة استعادية لـ ال7 مريضاً مصابين بالنزيف المخى الحاد تحت ألام الجافية فى قسم جراحة المخ والأعصاب بجامعة القاهرة

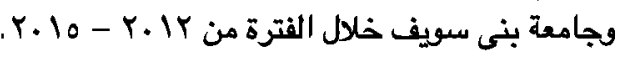

$$
\begin{aligned}
& \text { المجموعة (أ): توفى عا مريضاً فى المستشفى، ونجا ع مع نتائج غير مواتية الحالة الخضرية، وبا نجوا مع نتائج إيجابية. }
\end{aligned}
$$

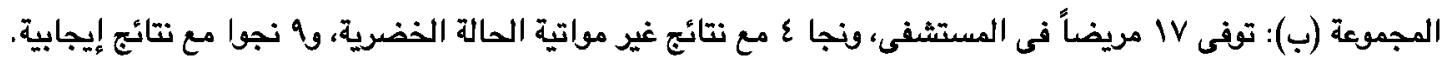

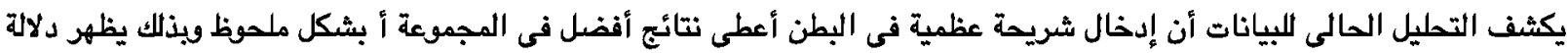

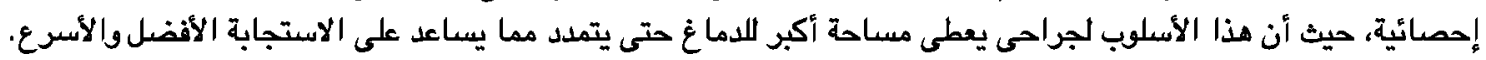

